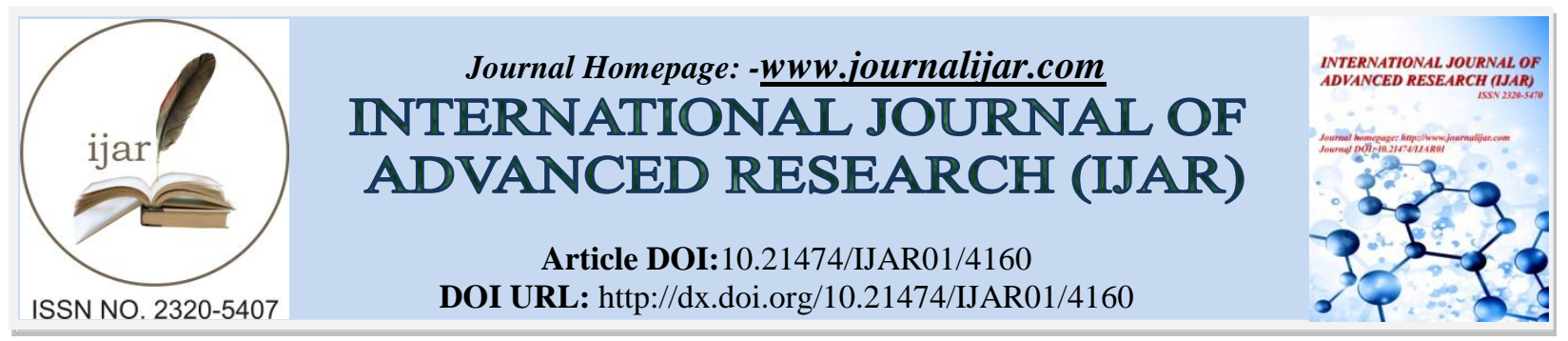

RESEARCH ARTICLE

\title{
ANTIOXIDANT AND ANTIBACTERIAL ACTIVITIES OF MENTHA ARVENSIS EXTRACT SDEPENDING ON ETHANOL CONCENTRATION.
}

\author{
Sam Woong Kim and Il-Suk Kim. \\ Department of Animal Resources Technology, Gyeongnam National University of Science and Technology, \\ Gyeongnam, 660-758, South Korea.
}

\section{Manuscript Info}

Manuscript History

Received: 16 March 2017

Final Accepted: 12 April 2017

Published: May 2017

Key words:-

Menthaarvensis, ethanol extract, antioxidant activity, antimicrobial activity, polyphenol, flavonoid.

\begin{abstract}
This study was performedto investigate antioxidant and antimicrobial activities of Menthaarvensisethanol extracts, whichwere extracted depending on ethanol concentrations. Yield of total extractshowed the highest level with $17.3 \%$ in the $30 \%$ ethanol extract. Total polyphenolic contentsin the $50 \%$ and $70 \%$ ethanol extracts wasdetected by relatively more amounts when compared withthose of theother extracts, whereas total flavonoid in $100 \%$ ethanol extract was showed by the most content. As a result consistent with the total polyphenol and flavonoid contents, the highest activities fromDPPH, ABTS and FRAP assayswere detectedinthe $70 \%, 100 \%$, and $50 \%$ ethanol extracts, respectively. Antimicrobial activities against Clostridium perfringens and Escherichia coli were strongly detected fromthe $70 \%$ and $100 \%$ ethanol extracts. Therefore, we suggest thattotal polyphenol and flavonoid contents from the $M$. arvensis ethanol extracts are directly associated with antioxidant and antibacterial activities.
\end{abstract}

Copy Right, IJAR, 2017,. All rights reserved.

\section{Introduction:-}

Recently, consumers have increased interest in the nutritional balance and safety for food, but not the quantity of food,with the improvement of educational and economic levels (Plastowet al. 2014; Sharma et al. 2015). Furthermore, average life expectancy has been extended by development of medical standards, and a growing interest in well-being has been increased the efforts to discover the functional food. However, since the discovery of functional materials are necessary to precede the development of functional food, manystudiesfor functional materials has beenmainly performed from natural products to be identified for safety (Mussatto 2014; Webb et al. 2004). Plant maintains a large number of variously useful components including secondary metabolites such as polyphenol and flavonoid compounds. However, since many parts have not yet been scientifically investigated to date, various natural resources in plant have beentried for search of the functional materials to have physiological activity (Lao et al. 2014; Lim et al. 2014; Qin et al. 2014; Wu et al. 2014). Recently, material research from natural products has been discovered antioxidantsas a part of the various functional food, which the antioxidants play important roles for maintenance of self-defense mechanism and for protectionof human body from active oxygen (Chen et al. 2010; Chaudhariet al. 2014).

Mint, Menthaarvensis, is a perennial plant belonging to family Lamiaceae. M. arvensis propagates via the long roots in underground as a perennial plant of 20 60 cmin height, and the leaves maintain many of parenchyma cells to 
carry a lot of essential oils. The various species of genus Menthagrow as wild plants in many places including Europe, Asia and North America. M. arvensisof a major-cultivated species is indigenous in Asia, but M. piperita is native in Europe region. The main components of peppermint have been well-known to methol, menthone, 1,8cineole, isomenthone, methyl acetate, neomenthol and limonene (Windholz 1983).

Peppermint has been often used as edible, medicinal and perfume main ingredients from ancient Egypt, and in a variety of symptoms such as indigestion, nausea, laryngitis, diarrhea, headache and abdominal pain in the East and West (Yoon et al. 2005). Peppermint maintains anti-inflammatory and anti-allergic activities and inhibitory effect of biofilm formation (Shin and Kim 1998; Sandasiet al. 2011;Lim et al. 2012). In addition, peppermint has been variously used for cookies, gum, cosmetics and toothpaste owing to specific refreshing feeling (Shin and Park 1994). The essential oil of peppermint is various efficacies such as analgesic, antiseptic, anti-excitement, removal of intestinal gas, strengthening of concentration, respiratory disease, mild anesthetic effect, normalization of ovarian function and dermatitis (Micklefieldet al. 2003; Kim 2006). The improvement of symptoms through inhalation of peppermint essential oil has been reported from anorexia and vomiting of cancer patients (Jung and Lee 2004; Woo 2010). On the other hand, the mint's essential oil is the inhibitory activities against Escheria coli, Helicobacter pyroli,Salmonella typhimuriumand Staphylococcus aureus (Lee et al. 2002; Woo et al. 2013).

In this study, as a preceding study for the application in the meat productsto induce an improved functionality, we prepared $M$. arvensisextracts depending on ethanol concentrations andexamined antioxidant and antibacterial activities for each extract.

\section{Materials and Methods:-}

\section{Preparation and yield of $M$. arvensisethanol extract:-}

M. arvensiswas purchased from traditional market in South Korea. Fifty grams ofaerial part were extracted by immersion for 1 week at room temperature with $0 \%, 30 \%, 50 \%, 70 \%$ and $100 \%$ ethanol concentrations. The extracts were filtered by Watman No.1 filterpaper, concentrated under vacuum in a rotary evaporator (RW-0252G 4000/G1, Heidolph, Germany), and then made into powder by lyophilization (PVTFD 10R, IlSinBioBase, Korea). Each extract after lyophilization was applied by dilution into $0 \sim 1,000 \mathrm{ug} / \mathrm{mL}$ for assay. Yields of the extracts depending on ethanol concentrations were presented by percent of lyophilized power/dried material (w/w) weight ratio.

\section{Determination of total polyphenol content:-}

Total polyphenol content was measured according to method of Peschelet al. (2006). An aliquot of the extract (0.1 $\mathrm{mL}$ of $100 \mu \mathrm{g} / \mathrm{mL}$ ) was mixed with $7.9 \mathrm{ml}$ of distilled water and $0.5 \mathrm{~mL}$ of Folin-Ciocalteu's phenol. After reaction for $2 \mathrm{~min}, 1.5 \mathrm{~mL}$ of $20 \%$ sodium carbonate solution was added, and then reacted for $2 \mathrm{~h}$. Total polyphenol content was measured by a microplate reader (Multiscan GO, Thermo Scientific co. ltd., USA) at $765 \mathrm{~nm}$ in wavelength. Total polyphenol content was presented asan $\mathrm{mg}$ galic acid/g equivalent.

\section{Determination of total flavonoid content:-}

Total flavonoid content was measured according to method of Chang et al. (2002). An aliquot of the extract (0.5 mL of $100 \mu \mathrm{g} / \mathrm{mL}$ ) was mixed with $1.5 \mathrm{~mL}$ of $95 \%$ ethanol, $0.1 \mathrm{~mL}$ of $10 \%$ aluminum chloride, $0.1 \mathrm{~mL}$ of $1 \mathrm{M}$ potassium acetate, and $2.8 \mathrm{~mL}$ of distilled water, and then reacted for $30 \mathrm{~min}$ at room temperature. Total flavonoid content was measured by a microplate reader (Multiscan GO, Thermo Scientific co. ltd., USA) at $415 \mathrm{~nm}$ in wavelength. Flavonoid content was presented as an $\mathrm{mg}$ catechine/g equivalent.

\section{DPPH radical scavenging activity:-}

DPPH radical scavenging activity was determined by reducing power of sample to a free radical scavenging for 2,2Diphenyl-1-picrylhydrazyl by a few modified method of Brand-Williams et al. (1995). The modified method was briefly described as follows. An aliquot of the extract $(500 \mu \mathrm{g} / \mathrm{mL})$ was well-mixed for 10 sec with the equivalent amount of DPPH (D9132, SIGMA, USA) solution, and after reaction for $20 \mathrm{~min}$, the treated solution was measured by a microplate reader (Multiscan GO, Thermo Scientific co. 1td., USA) at $517 \mathrm{~nm}$ in wavelength. Ascorbic acid and butylatedhydroxyanisole (BHA) were employed as positive controls. Free radical scavenging activity was presented by absorbance ratio between sample and control, and calculated as follows:

DPPHradical scavenging capacity $(\%)=(1-(\mathrm{AS}-\mathrm{AS} 0) / \mathrm{A} 0) \times 100 \%$

Where A0 is the absorbance of the negative control group without sample, ASO is the absorbance of the sample solution and AS is the absorbance of the treatment group with sample. 


\section{ABTS $^{+}$radical scavenging activity:-}

$\mathrm{ABTS}^{++}$radical cation discoloration assay was examinedfor the radical scavenging activity of the mint extract according to method of Re et al. (1999). The ABTS ${ }^{+}$stock solution (A9941-100TAB, SIGMA, USA)was diluted by $50 \%$ ethanol solution to prepare anABTS ${ }^{+}$working solution. The $\mathrm{ABTS}^{-+}$working solution was adjusted to $0.700 \pm 0.05$ at $732 \mathrm{~nm}$ in wavelength at room temperature. An aliquot of the extract $(2 \mu \mathrm{L}$ of $500 \mu \mathrm{g} / \mathrm{mL})$ was mixed with $50 \mu \mathrm{L}$ of $\mathrm{ABTS}^{-+}$working solution, reacted for $10 \mathrm{~min}$, and then measured by a microplate reader (Multiscan GO, Thermo Scientific co. Itd., USA) at $734 \mathrm{~nm}$ in wavelength. Ascorbic acid and butylatedhydroxyanisole (BHA) were employed as controls. Cation radical scavenging was presented by absorbance ratio between sample and control, and calculated as follows:

$\mathrm{ABTS}^{+}$radical scavenging capacity $(\%)=(1-(\mathrm{AS}-\mathrm{AS} 0) / \mathrm{A} 0) \times 100 \%$

Where A0 is the absorbance of the negative control group without sample, AS0 is the absorbance of the sample solution and AS is the absorbance of the treatment group with sample.

\section{FRAP assay:-}

FRAP (ferric-reducing antioxidant power) assay was determined depending on method of Benzie et al. (2006). The extract $(500 \mu \mathrm{g} / \mathrm{mL})$ was reacted with FRAP solution [0.3 M sodium acetate buffer (pH 3.6), $10 \mathrm{mM}$ TPTZ (2,4,6tris(2-pyridyl)- s-triazine) and $20 \mathrm{mM} \mathrm{FeCl}{ }_{3} \cdot 6 \mathrm{H}_{2} \mathrm{O}$ by ratio of 10:1:1], and then measured by a microplate reader (Multiscan GO, Thermo Scientific co. ltd., USA) at $595 \mathrm{~nm}$ in wavelength. FRAP activity was determined asan uM $\mathrm{FeSO}_{4} \cdot 7 \mathrm{H}_{2} \mathrm{O} / \mu \mathrm{g}$ equivalent.

\section{Determination of antibacterial activity:-}

Antibacterial activity was examined by $8 \mathrm{~mm}$ disc dispersion method (Barry 1976). The ethanol extractswere dissolved by $20 \mathrm{mg} / \mathrm{mL}$ concentrations. The applied bacteria including Staphylococcus aureus(ATCC 112692), Clostridium perfringens(ATCC 13124), Salmonella typhimurium(ATCC 14028), Escherichia coli (ATCC 11775), Listeria monocytogenes(ATCC 19114), Bacillus cereus (ATCC 1178), Vibrio parahaemolyticus(ATCC 17802D-5), and Candida albicans(ATCC 1023) were allocated from KCTC (Korean Collection for Type Cultures). The allocated bacteria were subcultured in Nutrient broth (Difco, USA). The subcultured bacteria were smeared on Nutrient agar, and positioned by $8 \mathrm{~mm}$ disc accumulated with $0.4,1,2$, and $4 \mathrm{mg}$ of each extract, and then incubated for $24 \mathrm{~h}$ at $37^{\circ} \mathrm{C}$. After incubation, antibacterial activity was calculated by size of clear zone around the disc.

\section{Statistics analysis:-}

Individual comparisons among least squares means (LSM) for significant differences were made according to the multiple range test of Duncan. All analyses were performed within the SAS statistical software package (version 9.1, SAS Inst., Inc., USA), and differences were considered significant at $P<0.05$.

\section{Results and Discussion:-}

Total polyphenol and flavonoid contents:-

In order to examine total extract yield depending on ethanol concentration, yieldsfrom $M$. arvensis were presented by weight ratio of dry extract/raw material. The yields extracted from $0 \%, 30 \%, 50 \%, 70 \%$ and 100\% ethanol concentrations were detected by $15.80,17.28,17.18,14.94$ and7.38\% (w/w), respectively (Fig. 1). As a result, the extract yield was the highest content at 30\% ethanol extract. Especially, it is assumed that the extremely low extraction yield in $100 \%$ ethanol is totally reduced owing to the low extraction yield of hydrophilic substances.

It has been well-known that polyphenolic compounds and flavonoids are closely associated with antioxidant activity (Macheixet al. 1990; Lee et al. 2002;Chung 1999; Fidriannyet al. 2013). Therefore, to analyze antioxidant activity in this study, we examined total polyphenol and flavonoid contents fromthe mint extracts (Table 1). Total polyphenols from the $50 \%$ and $70 \%$ ethanol extracts were detected by relatively high contents, 74.97 and $77.86 \mathrm{mg}$ gallic acid/g, respectively, whereas total flavonoid in $100 \%$ ethanol was extracted to the most content, $62.51 \mathrm{mg}$ catechin/g.

Taken together, it is estimated that the 50,70 and 100\% ethanol extracts to maintain high polyphenol and flavonoid contents are related with high antioxidant activities. 


\section{DPPH radical scavenging activity:-}

DPPH activity was examined for analysis of free radical scavenging ability from the mint extracts. DPPH activity depending on ethanol concentration was showed at Fig. 2. DPPH activities of the extracts exhibited totally lower values than those of ascorbic acid and BHA, but the 70\% ethanol extract to maintain the most total phenolic content exhibited the strongest DPPH radical scavenging activity among the extracts. This result is consistent with a report that the activity increases proportional to the polyphenol content from the correlation between antioxidant content and free radical scavenging activity (Chung 1999).

Furthermore, in this study, the $30 \%$ and $50 \%$ ethanol extracts to maintain comparative high polyphenol content were detected by comparative highDPPH radical scavenging activities among the extracts. However, although total polyphenol content in the 0\% (cold-water) ethanol extract was detected by a value higher than that of the $100 \%$ ethanol extract, the $0 \%$ ethanol extract showed the lowest value of DPPH activity. It is assumed that the extracted materials in $0 \%$ ethanol concentration have differential chemical properties to exhibit differential DPPH activity with the other ethanol extracts. Therefore, we suggest that polyphenoliccompoundsin the mint extract is directly associated with DPPH radical scavenging activity.

\section{$\mathrm{ABTS}^{++}$radical scavenging activity:-}

We examined $\mathrm{ABTS}^{++}$activity to analyze anionic free radical scavenging activity. ABTS ${ }^{+}$radical scavenging activities of the mint extracts depending on ethanol concentration were shown in Fig. 2. The highest activity was detected by the $100 \%$ ethanol extract with $9.65 \%$, and the $70 \%$ ethanol extract was observed by relatively high value.

Flavonoidshave antioxidant abilities by various patterns according to extraction solvent or extract materials, and in particular the materials extractedfrom $n$-hexane are associated with high ABTS $^{++}$radical scavenging activity (Fidriannyet al. 2013). In addition, the prenylated flavonoid reactsstrongly with $\mathrm{ABTS}^{++}$radical, but does not react with DPPH radical (Lee et al. 2006). Since anionic radical scavenging ability in this study was detected by relatively high values from the $70 \%$ and $100 \%$ extracts amongthe $M$. arvensisethanol extracts,and it is predicted which the $70 \%$ and $100 \%$ ethanol extracts contain lower polarities than those of the other extracts in this study, we suggest that materials to have relatively low polarity in the extracted fractions maintain $\mathrm{ABTS}^{-+}$radical scavenging activity. When compared with ascorbic acid, very low activities were totally observed in the extracts, but the $70 \%$ and $100 \%$ extracts showed activities higher thanthat of BHA.

From these results, we suggest that $\mathrm{ABTS}^{+}$activity is associated with flavonoid content because of maintaining relatively high flavonoid content in the $70 \%$ and $100 \%$ ethanol extracts when compared with the other extracts.However, since the $0 \%$ ethanol extract showed the lowest value of $\mathrm{ABTS}^{-+}$activity,in the same way as in the DPPH activity,it is assumed that the extracted materials in the $0 \%$ ethanol have differential chemical properties to show differential $\mathrm{ABTS}^{++}$activity with the other ethanol extracts.

\section{FRAP activity:-}

We examined to analyze Ferric-reducing antioxidant power (FRAP; \%) from the mint extracts. FRAP activities for the mint extract depending on ethanol concentration were presented at Fig. 4. FRAP activities of the extracts were totally detected by very lower levels when compared with ascorbic acid and BHA. However, among activities of the extracts, the $50 \%$ ethanol extract was showed by relatively high value.

Phenolic compound is a secondary metabolite to maintain the most abundance in fruit as hydrophilic antioxidants (Macheixet al. 1990). Antioxidant activities measured by DPPH and FRAP assays are highly associated with total polyphenol contents in nectarines, peaches and plums (Gil et al. 2002). Furthermore, the correlation between total polyphenol content and antioxidant activity is determined by FRAP or electron spin resonance spectroscopy in fruit juices (Gardner et al. 2000). Therefore, we suggest that the higher antioxidant activities of the 0,30, 50 and $70 \%$ ethanol extracts than that of the $100 \%$ extract are owing to higher total polyphenol content.

\section{Antibacterial activity:-}

In order to examine antibacterial activities from the extracts, we evaluated antibacterial activities by various bacterial strains including Gram positive, Gram negative and yeast. Antibacterial activities of the mint extracts depending on ethanol concentration was shown at Table 2. The results of clear zone assays surrounding disc appeared antibacterial activity against $C$. perfringensfrom all the extracts, except for the $0 \%$ extract. Especially, the 
$70 \%$ and $100 \%$ extracts showed strong activitiesagainst $C$. perfringens. On the other hand, the $70 \%$ and $100 \%$ extracts showed strong activities against $E$. coli. However, we didn't observe the activities against the other-applied strains.

The peppermint oil is potential antibacterial activities against pathogenic bacteria including $H$. pyroli and $S$. aureus (Woo et al. 2013). As the peppermint contains many contents of isomenthol (26.84\%) and menthol (25.48\%), the oil presents excellent antibacterial activities against $E$. coli and $S$. typhimurium(Lee et al. 2002). Therefore, we suggest that the extracts applied for this study have differential activity with the previous study due to the differentially extracted components depending on solvent used for extraction.

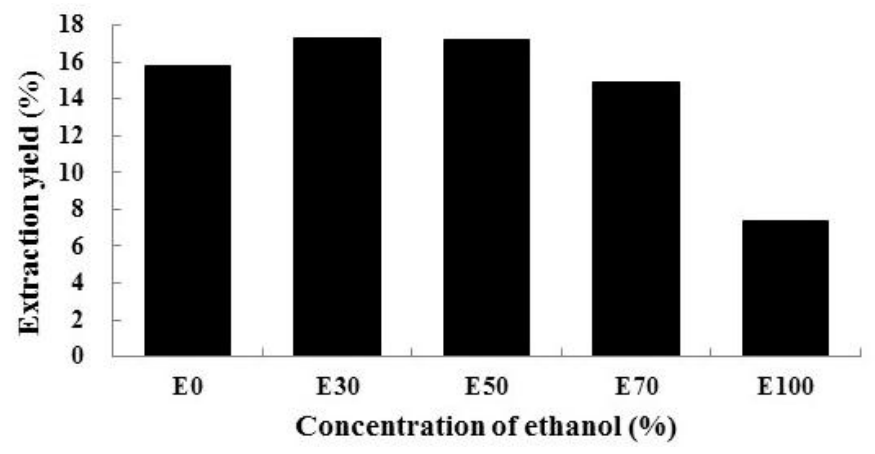

Fig. 1:- Extraction yields of $M$. arvensisdepending on ethanol concentration. The quantified $M$. arvensis was extracted depending on each ethanol concentration. $\mathrm{X}$ - and $\mathrm{Y}$-axes indicate ethanol concentration and extraction yield, respectively. E0; cold-water extract (0\% ethanol), E30, E50, E70 and E100; 30, 50, 70 and $100 \%$ ethanol extracts, respectively.

$\mathbf{A}$

\begin{tabular}{|c|c|c|c|c|c|}
\hline AA & E0 & 30E & 50E & 70E & 100E \\
\hline $57.7 \pm 1.48$ & $119.54 \pm 3.07$ & $109.05 \pm 3.31$ & $96.98 \pm 1.21$ & $104.95 \pm 5.02$ & $231.74 \pm 4.88$ \\
\hline
\end{tabular}

\section{B}

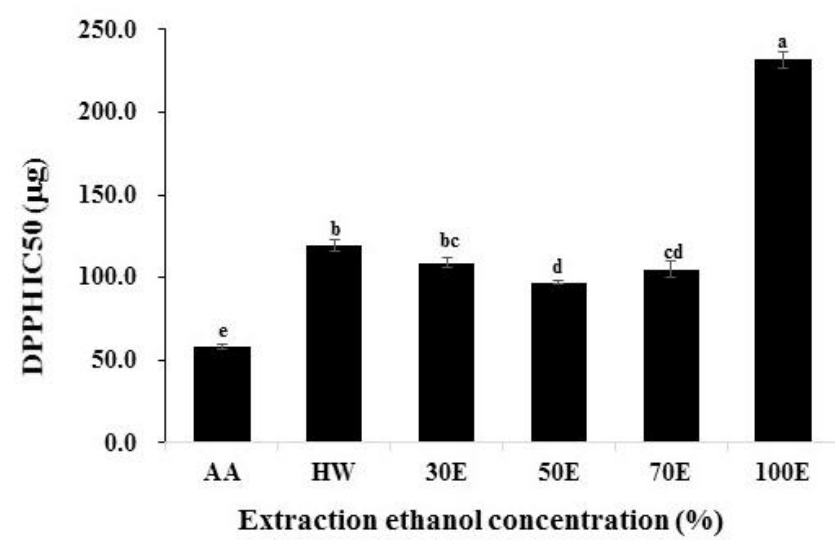

Fig. 2:- DPPH radical scavenging activities of the $\boldsymbol{M}$. arvensisethanol extracts. The extracts of $0,1,10,50,100$ and $1,000 \mu \mathrm{g} / \mathrm{mL}$ were applied for assay of DPPH. X- and Y-axes indicate ethanol concentration and 50\% inhibitory concentration (IC50) of DPPH radical scavenging activity, respectively. Ascorbic acid (AA) was applied as a positive reference for DPPH activity. E0; cold-water extract (0\% ethanol), E30, E50, E70 and E100; 30, 50, 70 and $100 \%$ ethanol extracts, respectively. ${ }^{\mathrm{a}-\mathrm{e}}$ Values indicate significant difference among the samples $(P<0.05)$. 


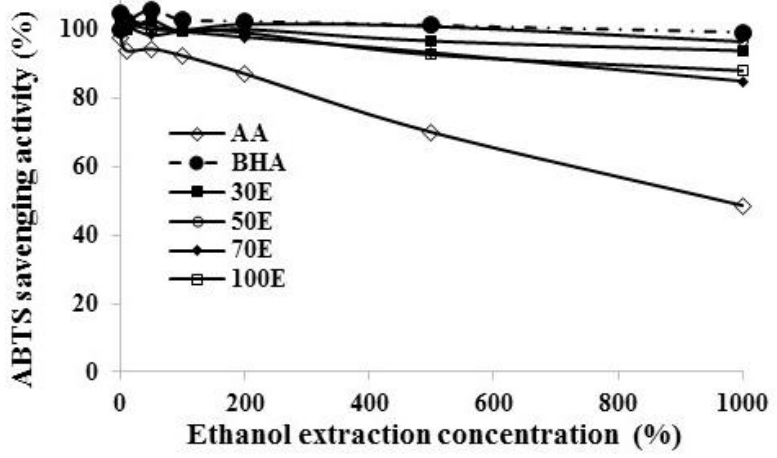

Fig. 3:- ABTS $^{+}{ }^{+}$adical scavenging activities of the $M$. arvensis ethanol extracts. The extracts of $0,1,10,50,100$ and $1,000 \mu \mathrm{g} / \mathrm{mL}$ were applied for assay of $\mathrm{ABTS}^{+}$. X- and Y-axes indicate ethanol concentration and $\mathrm{ABTS}^{+}$ radical scavenging activity, respectively. Ascorbic acid (AA) and BHA were applied as positive references for ABTS $^{+}$activity. E0; cold-water extract (0\% ethanol), E30, E50, E70 and E100; 30, 50, 70 and 100\% ethanol extracts, respectively.

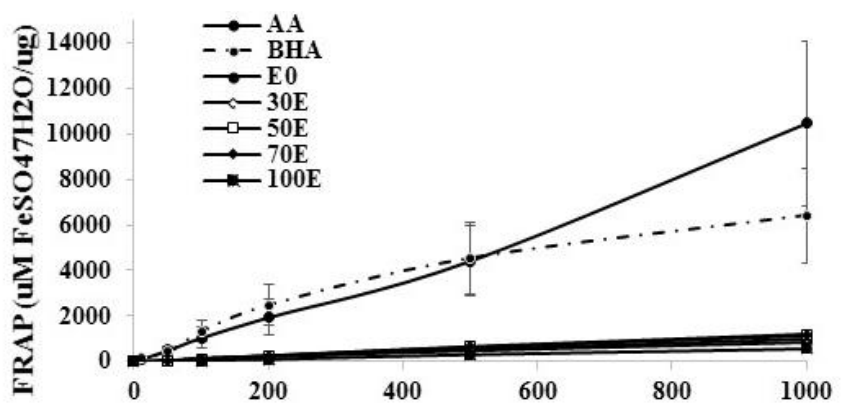

Extraction ethanol concentration (\%)

Fig. 4:- Assays for Ferric reducing ability of power fromthe $M$. arvensisethanol extracts. The extracts of 0,1 , $10,50,100$ and $1,000 \mu \mathrm{g} / \mathrm{mL}$ were applied for FRAPassay. X- and Y-axes indicate ethanol concentration and FRAP activity, respectively. Ascorbic acid (AA) and BHA were applied as positive references for FRAP activity. E0; coldwater extract (0\% ethanol), E30, E50, E70 and E100; 30, 50, 70 and 100\% ethanol extracts, respectively.

Table 1:- Total polyphenol and flavonoid contents from the Menthaarvensis ethanol extracts

\begin{tabular}{|c|c|c|}
\hline Applied ethanol concentration (\%) & Total polyphenol (mg GAE/g) & Total flavonoid (mg QE/g) \\
\hline 0 & $12.69 \pm 0.15^{\mathrm{b}}$ & $1.52 \pm 0.05^{\mathrm{b}}$ \\
\hline 30 & $12.90 \pm 0.44^{\mathrm{b}}$ & $0.08 \pm 0.01^{\mathrm{d}}$ \\
\hline 50 & $14.28 \pm 0.17^{\mathrm{a}}$ & $0.40 \pm 0.10^{\mathrm{c}}$ \\
\hline 70 & $14.74 \pm 0.23^{\mathrm{a}}$ & $3.42 \pm 0.07^{\mathrm{b}}$ \\
\hline 100 & $7.07 \pm 0.08^{\mathrm{c}}$ & $3.15 \pm 0.11^{\mathrm{a}}$ \\
\hline \multicolumn{2}{|c}{} \\
\hline \multicolumn{2}{|c|}{ Means \pm SD indicate significant difference within the same row. } \\
\hline
\end{tabular}

Table 2:- Antimicrobial activities tothe Menthaarvensisethanolextracts

\begin{tabular}{|c|c|c|c|c|c|c|c|c|c|c|c|c|c|c|c|c|c|c|c|c|c|}
\hline \multirow{2}{*}{\multicolumn{2}{|c|}{\begin{tabular}{|l|} 
Extract type \\
concentration $(\mathrm{mg})$
\end{tabular}}} & \multicolumn{4}{|c|}{ E0 } & \multicolumn{4}{|c|}{ E30 } & \multicolumn{4}{|c|}{ E50 } & \multicolumn{4}{|c|}{ E70 } & \multicolumn{4}{|c|}{ E100 } \\
\hline & & 0.4 & $\mathbf{1}$ & 2 & 4 & 0.4 & $\mathbf{1}$ & 2 & 4 & 0.4 & 1 & 2 & 4 & 0.4 & 1 & 2 & 4 & 0.4 & 1 & 2 & 4 \\
\hline \multirow[t]{8}{*}{$\begin{array}{l}\text { Micro } \\
\text { orga- } \\
\text { nisms }\end{array}$} & E. coli & - & - & - & - & - & - & - & - & - & 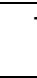 & - & - & - & $\begin{array}{l}++ \\
+\end{array}$ & $\begin{array}{l}++ \\
++ \\
+\end{array}$ & $\begin{array}{l}++ \\
++ \\
+\end{array}$ & - & $\begin{array}{l}++ \\
+\end{array}$ & $\begin{array}{l}++ \\
++ \\
+\end{array}$ & $\begin{array}{l}++ \\
++ \\
+\end{array}$ \\
\hline & S. typhimurium & - & - & - & - & - & - & - & - & - & - & - & - & - & - & - & - & - & - & - & - \\
\hline & V.parahaemolyticus & - & - & - & - & - & - & - & - & - & - & - & - & - & - & - & - & - & - & - & - \\
\hline & B. cereus & - & - & - & - & - & - & - & - & - & - & - & - & - & - & - & - & - & - & - & - \\
\hline & C. perfringens & - & - & - & - & - & - & - & $\begin{array}{l}++ \\
++ \\
+\end{array}$ & - & - & - & $\begin{array}{l}++ \\
++ \\
+\end{array}$ & ++ & $\begin{array}{l}++ \\
++\end{array}$ & $\begin{array}{l}++ \\
++ \\
+\end{array}$ & $\begin{array}{l}++ \\
++ \\
+\end{array}$ & $\begin{array}{l}++ \\
+\end{array}$ & $\begin{array}{l}++ \\
++\end{array}$ & $\begin{array}{l}++ \\
++ \\
+\end{array}$ & $\begin{array}{l}++ \\
++ \\
+\end{array}$ \\
\hline & L. moncytogenes & - & - & - & - & - & - & - & - & - & - & - & - & - & - & - & - & - & - & - & - \\
\hline & S. staphylococcus & - & - & - & - & - & - & - & - & - & - & - & - & - & - & - & - & - & - & - & - \\
\hline & C. albicans & - & - & - & - & - & - & - & - & - & - & - & - & - & - & - & - & - & - & - & - \\
\hline
\end{tabular}


*Escheria coli (ATCC 11775), Salmonella typhimurium (ATCC 14028), Vibrio parahaemolyticus (ATCC 17802D5), Clostridium perfringens (ATCC 13124), Bacillus cereus (ATCC 1178), Listeria monocytogenes (ATCC 19114), Staphylococcus aureus (ATCC 112692), and Candida albicans (00 432 ATCC 1023 IFO 1594). ** -; No antimicrobial activity, +; Very slight anitimicrobial activity toclear zoneof 8.1-9.0 mm diameter, ++ ; Moderate antimicrobial activity to clear zone of 9.1-10.9 mm; +++; Clear antimicrobial activity to clear zone of 11.0-12.9 mm; ++++ ; Strong antimicrobial activity to clear zone of 13.0-15.9 mm; +++++ ; Very strong antimicrobial activity to clear zone above16.0 $\mathrm{mm}$.

\section{Conclusions:-}

The yield of extraction for $M$. arvensis appeared the most amount at the $30 \%$ ethanol extract. Total polyphenol content was detected by relatively high values at the 50 and $70 \%$ ethanol extracts, whereas total flavonoid content was showed by the most amount at the $100 \%$ ethanol extract. As a result consistent with these contents, DPPH, ABTS and FRAP activities were assayed by the highest values at the 70, 100 and 50\% extracts, respectively. However, ABTS and FRAP activities, except for the activity of DPPH, were very low in comparison with ascorbic acid and BHA. Antibacterial activity was detected only for E. coli and C. perfringens.

\section{Acknowledgements:-}

This work was supported by Gyeongnam National University of Science and Technology Grant 2016.

\section{References:-}

1. BARRY, A.L. 1976. In The antimicrobic susceptibility test: principles and practices. Philadelphia: Lea \&Febiger. 92-104.

2. BENZIE, I.F. and STRAIN, J.J. 1996. The ferric reducing ability of plasma (FRAP) as a measure of "antioxidant power": the FRAP assay. Anal.Biochem. 239, 70-76.

3. BRAND-WILLIAMS, W., CUVELIER, M.E. and BERSET, C. 1995. Use of a free radical method to evaluate antioxidant activity. LWT-Food Sci. Technol. 28, 25-30.

4. CHANG, C.C., YANG, M.H., WEN, H.M. and CHERN, J.C. 2002. Estimation of Total Flavonoid Content in Propolis by Two Complementary Colorimetric Methods. J. Food Drug Anal. 10, 178-182.

5. CHAUDHARI, P., YE, Z. and JANG, Y.Y. 2014. Roles of reactive oxygen species in the fate of stem cells.Antioxid. Redox Signal.20,1881-1890.

6. CHEN, C.T., HSU, S.H. and WEI, Y.H. 2010. Upregulation of mitochondrial function and antioxidant defense in the differentiation of stem cells.Biochim. Biophys. Acta. 1800,257-263.

7. CHUNG, S.Y., KIM, N.K. and YOON, S. 1999. Nitrite scavenging effect of methanol fraction obtained from green yellow vegetable juices. J. Korean Soc. Food Sci. Nutr. 28, 342-347.

8. FIDRIANNY, I., RAHMIYANI, I. and WIRASUTISNA, K.R. 2013. Antioxidant activities from various leaves extracts of four varieties mangoes using DPPH, ABTS assays and correlation with total phenolic, flavonoid, carotenoid. International Journal of Pharmacy and Pharmaceutical Sciences. 5, 189-194.

9. GARDNER, P.T., WHITE, T.A.C., MCPHAIL, D.B. and DUTHIE, G.G. 2000. Therelative contributions of vitamin $\mathrm{C}$, carotenoids and phenolics to theantioxidant potential of fruit juices. Food Chemistry. 68, 471-474.

10. GIL, M.I., TOMAS-BARBERAN, F.A., HESS-PIERCE, B. and KADER, A.A., 2002.Antioxidant capacities, phenolic compounds, carotenoids, and vitaminC contents of nectarine, peach, and plum cultivars from California.Journal of Agricultural and Food Chemistry. 50, 4976-4982.

11. JUNG, E.S. and LEE, B.S. 2004. Effect of aroma oil inhalation on nausea vomiting and anorexia in cancer patients receiving chemotherapy. J. Kor. Acad. Adult Nurs. 16, 135-145.

12. KIM, K.R. 2006. Clinical observation of aromatheraphy on the headache patients. Thesis for the degree of master. Chosun Univ. Korea.

13. LAO, Y., WANG, X., XU, N., ZHANG, H. and XU, H. 2014. Application of proteomics to determine the mechanism of action of traditional Chinese medicine remedies. J. Ethnopharmacol. 155, 1-8.

14. LEE, B.W., LEE, J.H., GAL, S.W., MOON, Y.H.and PARK, K.H. 2006. Selective ABTS radical-scavenging activity of prenylated flavonoids from Cudraniatricuspidata.Biosci. Biotechnol. Biochem. 70, 427-432.

15. LEE, S.E., PARK, C.G., CHA, M.S., KIM, J.K., SEONG, N.S., BANG, K.H. and BANG, J.K.2002. Antimicrobial activity of essential oils from Menthaarvensis L. var. piperascensMalivaud and Agastacherugosa O. Kuntze on Escherichia coli and Salmonella typhimurium.Korean J. Medicinal Crop Sci. 10, $206-211$. 
16. LIM, C., PARK, S., SUN, S. and LEE, K. 2014. Research on Korean Pharmacopuncture in South Korea since 2007. J. Pharmacopuncture. 17, 15-21.

17. LIM, H.S., KIM, J.H., HA, H., SEO, C.S. and SHIN, H.K. 2012. Comparative study of the anti-inflammatory effects of Menthaeherba from korea and China. Kor. J. Pharmacogn. 43, 231-238.

18. MACHEIX, J.J., FLEURIET, A. and BILLOT, J. 1990. Fruit Phenolics. CRC Press,Boca Raton, FL.

19. MICKLEFIELD, G., JUNG, O., GREVING, I. and MAY, B. 2003. Effects of intraduodenal application of peppermint oil (WS 1340) and caraway oil (WS 1520) on gastroduodenal motility in healthy volunteers. Phytotherapy Res. 17, 135-140.

20. MUSSATTO, S.I. 2014. Brewer's spent grain: a valuable feedstock for industrial applications.J. Sci. Food Agric. 94,1264-1275.

21. PESCHEL, W., SANCHEZ-RABANEDA, F., DIEKMANN, W., PLESCHER, A., GART-ZIA, L., JIMENEZ, D. M., LAMUELA-RAVENTOS, R., BUXADERAS, S. and CODINA, C. 2006. An industrial approach in the search of natural antioxidants from vegetable and fruit wastes. Food Chem. 97, 137-150.

22. PLASTOW, N.A., ATWAL, A. and GILHOOLY, M. 2014. Food activities and identity maintenance in old age: a systematic review and meta-synthesis.Aging Ment. Health. 6, 1-12.

23. QIN, K.M., WANG, B., CHEN, L.W., ZHANG, M.S., YANG, G.M., SHU, Y.C. and CAI, B.C. 2014. [Perspective and application of metabonomics in modern study of traditional Chinese medicine]. ZhongguoZhong Yao ZaZhi. 39, 3010-3017.

24. RE, R., PEllegrin, V., PROTEGGENTE, A.R., PANNALA, A., YANG, M. and CATHERINE, R.E. 1999. Antioxidant activities applying an approved ABTS radical caution decolorization assay. Free radical Biology \& Medicine. 26, 1231-1237.

25. SANDASI, M., LEONARD, C.M., VAN VUUREN, S.F. and VILJOEN, A.M. 2011. Peppermint (Menthapiperita) inhibits microbial biofilms in vitro. South African Journal of Botany. 77, 80-85.

26. SHARMA, T.K., RAMANATHAN, R., RAKWA, L.R., AGRAWAL, G.K. and Bansal, V. 2015. Moving forward in plant food safety and security through NanoBioSensors: Adopt or adapt biomedical technologies?Proteomics. doi: 10.1002/pmic.201400503. Epub ahead of print.

27. SHIN, T.Y. and KIM, D.K. 1998. Antiallergic activity of Menthaeherba. Kor. J. Pharmacog. 29, $248-253$.

28. SHIN, K.E. and PARK, H.K. 1994. Changes of essential oils from Menthapiperita L. influenced by various cultivation conditions and harvesting time. J. Kor. Food Sci. Technol. 26, 512-519.

29. WEBB, C, KOUTINAS, W.R. and WANG, R.2004. Developing a sustainable bioprocessing strategy based on a generic feedstock.Adv. Biochem. Eng. Biotechnol.87,195-268.

30. WINDHOLZ, M. 1983. The merck index. 10th. New Jewrsey: Merck \& Co. Inc.

31. WOO, J.H. 2010. Antioxidant and antimicrobial activities from functional components of major commercial herb essential oil products in korea and foreign countries. Thesis for the degree of doctor of philosophy. Korea Univ. Korea.

32. WOO, J.H., LEE, S.Y., KIM, J.H. and PARK, K.W. 2013. Antioxidant and antimicrobial activity of peppermint oil products. J. Korean Soc. People Plants Environ. 16, 361-367.

33. WU, W.Y., HOU, J.J., LONG, H.L., YANG, W.Z., LIANG, J. and GUO, D.A. 2014. TCM-based new drug discovery and development in China. Chin. J. Nat. Med. 12, 241-250.

34. YOON, J.H., SONG, W.S., KIM, E.S. and PARK, J.S. 2005. Effect of plant growth regulators on antioxidant activity of peppermint. J. Kor. Res. Plant. 18, 187. 